\title{
Un arte fantasma: perspectivas en torno a la teoría y la historia de la dirección teatral.
}

\author{
Eugenio Schcolnicov \\ Facultad de Filosofía y Letras, Universidad de Buenos Aires \\ eugeniobuzon@gmail.com \\ Artículo bajo licencia Creative Commons \\ Atribución 4.0 Internacional (CC BY 4.0) \\ ENVIADO: $2021-12-20$ \\ ACEPTADO: 2021-05-31
}

\section{RESUMEN}

El siguiente trabajo elabora un relevamiento crítico de una serie paradigmas contemporáneos sobre la dirección teatral. Diferenciaremos cinco propuestas conceptuales: el concepto de mise-en-scène (Pavis); el director como auteur (Sidiropoulou); la dirección como un proceso de artificación (Proust) y el estudio de los marcos institucionales que la definen (Rebellato y Delgado); el concepto Regie (Boenisch); por último, las exploraciones genéticas sobre el oficio del director desde la neuroestética y la teoría de la creatividad (Ledger). Posteriormente, analizaremos cómo los paradigmas relevados permiten configurar una teoría para historizar las prácticas de la dirección teatral en América Latina..

\section{RESUMO}

O trabalho seguinte elabora um levantamento crítico de uma série de paradigmas contemporâneos sobre a direcção teatral. Vamos diferenciar cinco propostas conceituais: o conceito de misé en scene (Pavis); o director como auteur (Siridopolou); a direcção como processo de artificação (Proust) e o estudo dos quadros institucionais que a definem (Rebellato e Delgado); o conceito Regie (Boenisch); finalmente, as explorações genéticas do ofício do director a partir da neuroestética e a teoria da criatividade (Ledger). Por último, veremos como os paradigmas por nós estudados nos permitem configurar uma teoria para historicizar as práticas de direcção teatral na América Latina.

\section{Palavras-chave}

PALABRAS CLAVE

Dirección Teatral - Historia del

Teatro - Puesta en Escena - Teatro Latinoaméricano.
Distória do teatro Encenação - Teatro na América Latina.

\section{ABSTRACT}

The following paper will critically survey a number of contemporary paradigms of theatre directing. We will distinguish five proposals: the concept of misé en scene (Pavis); the director as auteur (Sidiropoulou); directing as a process of artification (Proust) and the study of the institutional frameworks that define it (Rebellato and Delgado); the Regie concept (Boenisch); finally, the genetic explorations of the director's craft from neuroaesthetics and the theory of creativity (Ledger). Lastly, we will see how the paradigms we have examined allow us to configure a theory to historicise theatrical directing practices in Latin America.

\section{KEYWORDS}

Theatre Directing - History of Theater Staging - Theater in Latin America. 


\section{INTRODUCCIÓN}

Desde su emergencia durante el siglo XIX, la identidad que define la dirección escénica y su territorio de acción han sido una ecuación difícil de desentrañar para los estudios teatrales. En gran medida, las teorías desarrolladas en torno al oficio del director y su lugar en el proceso de producción dan cuenta de una compleja diversidad, construyendo categorías heterogéneas según los distintos contextos históricos y culturales en los cuales este campo de reflexión se hizo presente.

Salvo contadas excepciones, en los estudios teatrales latinoamericanos no abundan trabajos dedicados a la historización o a la teorización de la dirección. Algunas aproximaciones parciales se encuentran en el extenso proyecto desarrollado por Gustavo Geirola (2014, 2015a, 2015b, 2015c), en los estudios de Osvaldo Pellettieri y su equipo de colaboradores (Pellettieri, 2001, 2002, 2003a, 2003b) y en los aportes recientes de investigadoras como Fwala-lo Marin $(2018,2020)$ y María Fukelman (2018). Deben destacarse también los análisis de la producción de un conjunto de directores y directoras teatrales argentinas en aquellos estudios que se orientan en la descripción de otros fenómenos escénicos (Mauro, 2011; Pinta, 2013). A la vez, dentro del territorio argentino, un amplio espectro de directores ha elaborado en los últimos años algunas producciones teóricas orientadas a pensar el trabajo de la dirección a partir de sus propias prácticas escénicas. Entre otros aportes, podemos enumerar los trabajos de Guillermo Heras (2014), Ruben Szuchmacher (2015) y Cipriano Argüello Pitt (2018).

En vistas a configurar una teoría que, desde la metodología de Poética teatral y el Teatro comparado (Dubatti, 2010), nos permita elaborar una historización de los procesos de la dirección en el teatro de Buenos Aires ${ }^{1}$, nos proponemos desarrollar a continuación un relevamiento crítico de una serie de paradigmas contemporáneos sobre la dirección escénica gestados en Europa y Norteamérica. Una primera aproximación nos permite diferenciar cinco grandes tendencias: aquellas que parten del concepto de mise-en-scène (Pavis, 2007); la comprensión del trabajo de la dirección teatral desde las teorías del auteurismo (Sidiropoulou, 2011); la dirección como un proceso de artificación (Proust, 2012, 2019) y el estudio de los marcos institucionales que la definen (Rebellato y Delgado, 2010); el concepto Regie y la definición de la dirección como un ejercicio de mediación, una práctica relacional y una forma de pensamiento (Boenisch, 2015); por último, las exploraciones genéticas sobre el oficio de la dirección desde la neuroestética y la teoría de la creatividad (Ledger, 2019). Cada una de las perspectivas que expondremos se debate entre el estudio de los efectos de la dirección desde la posición del espectador o el analista, entendido como un objeto teórico de conocimiento, y la comprensión de las múltiples funciones y tareas que la dirección ejecuta, abogando por una mirada que intente comprender el rol del director desde una perspectiva genética del espectáculo y de su dimensión empírica. Otra discusión central que se advierte en las teorías seleccionadas refiere al vínculo que la producción del espectáculo mantiene con el texto dramático y su jerarquía. En tercer lugar, cada una de las miradas expuestas comprende el trabajo de dirección a partir de un evidente anclaje territorial: la forma de concebir la dirección es deudora en cada caso de las formas de leer el teatro desde las propias coordenadas geográficas y culturales de los analistas, lo que determina variaciones en torno al origen de la dirección teatral como un oficio autónomo y definido. Veremos, por lo tanto, en qué medida los paradigmas relevados permiten configurar una teoría de la dirección teatral capaz de pensar las prácticas escénicas en la pluralidad de los territorios latinoamericanos y construir las bases para un estudio de las poéticas de la dirección teatral en nuestro continente.

Este trabajo se inscribe dentro del proyecto de tesis de doctorado Poéticas de la dirección teatral en el teatro argentino de Buenos Aires durante la última dictadura militar (1976-1983): formas de producción, construcción de sentido político y género. 


\section{MISE-EN-SCÈNE: ENTRE SEMIOLOGÍA Y FENOMENOLOGÍA}

Tal como observa Ezequiel Lozano (2008), La mise en scène contemporaine. Origines, tendances, perspectives (2007) cierra una trilogía teórica elaborada por Patrice Pavis que tiene como antecedentes L'Analyse des spectacles (1996) y Le theàtre contemporain. Analyse des textes de Sarraute à Vinaver (2002). En este estudio, el núcleo para comprender la dirección teatral se encuentra en el concepto de mise-en-scène, y su articulación con las teorías de la performance y las tendencias deconstructivistas que han emergido en el teatro europeo de las últimas décadas.

Desde la perspectiva de Pavis, si bien puede hablarse de puesta en escena durante el período de la revolución francesa, la definición acabada de este concepto y sus funciones deben situarse a partir de 1880. De allí en adelante se advierte en el campo teatral una "ruptura epistemológica" en la cual la mise-en-scène adquiere un estatuto autónomo y específico, distinto del concepto de representación (mimesis) y de espectáculo (opsis). La puesta en escena constituye entonces un nuevo fenómeno, definido como "una representación bajo la forma de un sistema de sentidos controlado por un director de escena o por un colectivo" ${ }^{2}$, y define desde sus orígenes una entidad abstracta que marca un antes y un después en la historia del teatro occidental: su emergencia afirma la presencia de un sujeto capaz de integrar la totalidad de los elementos dispuestos en la escena desde una posición dominante. Esta condición abstracta impide aproximarse a la dirección desde una indagación genética del espectáculo, aspecto que, como veremos, será objetado por otros estudios posteriores. Ya sea a través de las innovaciones escénicas desplegadas por la estética naturalista de Antoine -que reconoce las cualidades inmateriales de la dirección teatral y de la puesta en escena como un dispositivo productor de sentido-, o a partir de la estética simbolista y su rechazo de toda materialidad, el concepto de mise-en-scène define una nueva organización autónoma del espectáculo teatral y no solamente el pasaje del texto a la escena.

Luego de esta primera definición, Pavis explora las sucesivas transformaciones de la mise-en-scène ante la expansión de las prácticas performativas y su teorización, marcadas por la objeción hacia la semiología y su comprensión de la puesta en escena como una mera lectura de signos (41). Ante el desarrollo de los performance studies, el investigador francés concibe a la mise en scène como una forma posible en la multiplicidad de las performances culturales, a través de una mirada que indaga de forma simultánea en la construcción estética y la objetivación antropológica. Se configura así una clara diferencia: mientras que la puesta en escena designa el pasaje del texto a la escena -la oposición entre lo visual y lo textual-, la performance, en su doble acepción, indica una acción ejecutada y el resultado de esa acción. ${ }^{3}$ Sin embargo, ambas nociones no son estáticas. De manera progresiva, la distancia entre el orden práctico y epistémico de la performance y el

“La mise en scène est donc une représentation sous l'aspect d'un système de sens contrôlé par un metteur en scène ou par un collectif" (2007: 15. La traducción es nuestra).

Para una clara diferenciación entre los conceptos de "Performance", "Performance Art”, "Cultural Performance" y "Performance Studies” véase Pavis (2016). de la puesta en escena encontrarán un territorio de convergencia. La evidencia que arroja el análisis de Pavis postula un diagnóstico sobre nuestra contemporaneidad: en el momento actual no es posible una teoría de la puesta en escena que no integre en su comprensión la reflexión de la performance theory en confluencia con el análisis semiológico. Por el contrario, el análisis de los espectáculos pasa de una semiología descriptiva a una fenomenología del sujeto perceptor. Pero este pasaje es más bien una alianza entre los dos métodos: la semiología es una herramienta indispensable para la descripción estructural del espectáculo, mientras que la fenomenología incluye activamente al espectador en su dimensión corporal y emocional ${ }^{4}$ (71).

Junto con la noción de performance y el campo de estudios que despliega, los estudios de la puesta en escena se enfrentan a otro gran desafío, a partir de su interacción con las teorías deconstructivistas y su manifestación en la práctica teatral. La descomposición de una estructura y el cuestionamiento sobre el fundamento y lo fundado pueden reconocerse en la puesta en escena contemporánea, cuya fragmentación, ambigüedad y descentramiento oscila entre la organización de un sistema coherente de signos y un acontecimiento cuyos límites no son del todo identificables (153). El análisis de algunos espectáculos realizados por una serie de directores como Antoine Vitez, Patrice Chéreau, Christoph Marthaler, Frank Castorf o Park Jung-Hee ponen de relieve la dialéctica entre deconstrucción y reconstrucción presente en el teatro contemporáneo. Pavis afirma que, en la actualidad, el director "ya no es el maestro de una subjetividad absoluta que se traduciría en todas las decisiones y las elecciones de la puesta en escena"5 (181). Sin embargo, lo que emerge de este cambio es una nueva centralidad que ubica al espectador en un lugar privilegiado: la deconstrucción se manifiesta para culminar en una nueva reconstrucción, reestableciendo el reino de la representación, la ficción, el signo y la clausura. Luego de las prácticas deconstructivistas, la puesta en escena en el teatro contemporáneo ya no aspira a ser legible o explicativa, sino que, por el contrario, se abre hacia la imprecisión y a la ambigüedad.

En sus conclusiones, Pavis mira retrospectivamente las diversas identidades que el director adquirió durante el siglo XX pero advierte la necesidad de no abandonar la noción ni el método que describe la puesta en escena, y aboga por un equilibrio entre la emisión y la recepción, a través de un esquema metodológico que se posicione en la frontera entre la semiología y la fenomenología, aspecto que también tendrá relevancia en las teorías orientadas hacia la comprensión del director como auteur.

“l'analyse des spectacles passe d'une sémiologie descriptive à une phénoménologie du sujet percevant. Mais ce passage est plutôt une alliance entre les deux méthodes, la sémiologie est un outil indispensable à la description structurale du spectacle, tandis que la phénoménologie inclut activement le spectateur dans sa dimension corporelle et émotionnelle" (la traducción es nuestra).

“celui-ci n'est plus au centre de tout, notamment du sens, il n'est plus le maître d'une subjectivité absolue qui se traduirait dans toutes les décisions et les choix de la mise en scène" (la traducción es nuestra). 


\section{DIRECCIÓN TEATRAL Y AUTEURISMO}

La comprensión del director como una figura de autoridad, capaz de disputarle el lugar de legitimidad plena y absoluta al dramaturgo, se manifiesta en el estudio Authoring Performance: The director in the contemporary theatre, de Avra Sidiropoulou (2011). Allí, la investigadora griega analiza la figura del director teatral en tanto creador y focaliza en el fenómeno particular del auteurismo. Los antecedentes de esta caracterización pueden identificarse en el estudio seminal desarrollado por Bradby y Williams (1988). Sidiropoulou expresa que, si bien el concepto de auteur nace en el seno de la crítica cinematográfica francesa durante la década del 50, sus categorías de análisis pueden proyectarse a la esfera teatral, sobre todo a partir de la segunda mitad del siglo XX. La perspectiva adoptada para pensar este fenómeno se asienta en la oposición definida por Pavis entre el imperio de la significación de la mise-en-scène y la dimensión fenomenológica que instituye la performance. Según la investigadora, el efecto estético de ciertas prácticas teatrales contemporáneas reside en la capacidad del director de establecer un equilibrio entre la significación y la dimensión fenoménica y material del espectáculo. Por lo tanto, el concepto de auteurismo sirve para definir el trabajo creativo de aquellos directores que adaptan, interfieren o deconstruyen el texto dramático original, o elaboran su propia dramaturgia, desarrollando un estilo único y una marca característica de su trabajo. Bajo esta categoría es posible identificar la producción de algunos creadores escénicos contemporáneos como Robert Wilson, Peter Sellars, Ivo Van Hove, Christoph Marthaler o Robert Lepage. Los antecedentes de estas prácticas se encuentran en el legado de algunos directores teatrales europeos a lo largo del siglo XX, entre los que se encuentran Alfred Jarry, Constantin Stanislavski, David Gordon Craig y Erwin Piscator. Junto a ellos, la autora se detiene en el pensamiento teórico de Antonin Artaud -quien reclama la comprensión de la performance teatral como una forma artística en su propio derecho-y en la introducción de elementos que sugieren indicaciones sobre la puesta en escena en los textos dramáticos de Samuel Beckett. Ambos ejemplos constituyen antecedentes fundamentales para la consolidación del director-auteur contemporáneo. A la vez, la afirmación de esta figura es producto de la autonomía conquistada por la escena y de la reconsideración del lugar del texto dramático en la totalidad del acontecimiento teatral (2011: 31).

Para Sidiropoulou, los aspectos más trascendentes y modernizadores que se identifican en las prácticas de los directores-autores residen en la desestabilización y la re-examinación de la dimensión semiótica del acontecimiento escénico, junto con algunas características específicas que se observan de forma variable y heterogénea en el corpus de creadores seleccionados para el estudio. Entre otras, la autora enumera: la preeminencia de la dimensión visual y el uso intensivo de los dispositivos escenográficos y lumínicos; la exploración sobre las coordenadas temporales, el ritmo y el sonido; el énfasis sobre la condición material de la performance; por último, la integración dominante de la tecnología en la experiencia escénica. El ejercicio de un nuevo tipo de escritura, construida a partir de la organización material de la escena, configura la dimensión autoral que Sidiropoulou advierte en la dirección contemporánea, capaz de desplazar al dramaturgo como autoridad última y centro principal de atención de la experiencia teatral. Según ella, "habiendo adquirido confianza en el cambio de énfasis del drama mimético y argumental hacia una representación basada en la imagen siempre fluida, en la que se combinan y chocan diversos medios, textualidades, culturas y estilos, los directores de vanguardia en Occidente han ido desarrollando sus propios métodos y sus idiomas escénicos singulares, contribuyendo al establecimiento resuelto del teatro de autor"6 (74). Sin embargo, pensar al director como autor y como demiurgo absoluto de la escena no inhibe la posibilidad de reconocer la incidencia que los dispositivos institucionales tienen en la configuración de su oficio.
6 "Having acquired confidence in this shifting of emphasis from mimetic, plot- driven drama to an ever- fluid image- based performance where various media, textualities, cultures, and styles combine and collide, avant- garde directors in the West have been developing their own singular methods and stage idioms, contributing to the resolute establishment of auteur theatre" (la traducción es nuestra). 


\section{ARTIFICACIÓN, MARCOS INSTITUCIONALES Y LEGITIMACIÓN}

Sin abandonar la comprensión del director como metteur en scène y auteur, las apreciaciones elaboradas por Dan Rebellato y María Delgado (2010), y por Serge Proust (2012, 2019) aportan nuevas perspectivas a la comprensión del oficio de la dirección en su interacción con los marcos institucionales que le otorgan visibilidad y legitimación. En su introducción al volumen Contemporary European Theatre Directors, Rebellato y Delgado afirman que los directores teatrales europeos se han erigido como líderes de grandes instituciones culturales, lo que les ha permitido en algunos casos reforzar las posiciones ideológicas hegemónicas o, por el contrario, ejecutar respuestas críticas a las cosmovisiones culturales dominantes. La integración institucional ha determinado que la figura del metteur en scène se fusione en algunos casos con la del directeur o el intendant, en tanto agente ejecutivo y emprendedor cultural, definiendo un vínculo sólido e inextricable entre los creadores escénicos y las instituciones culturales que conducen y administran. De forma simultánea, los investigadores observan un segundo fenómeno: mientras que la identificación del director con una determinada cultura nacional resultó central en las experiencias teatrales de posguerra, los directores del presente expresan una clara reticencia para responder desde su propio trabajo a las agendas de los estados nacionales. Por lo tanto, obtener una perspectiva de la dirección teatral implica integrar las transformaciones que la experiencia de globalización e hibridación cultural construye sobre las prácticas teatrales y, en particular, sobre el lugar del lugar del director. El estudio de Rebellato y Delgado ilumina también un aspecto central del oficio de la dirección desde sus inicios: la doble figura del director como pedagogo y maestro de actores, presente en gran cantidad de directores contemporáneos como Daniel Mesguich, Lev Dodin, Thomas Ostermeier, Declan Donellan o Katie Mitchell. Para un amplio espectro de directores, las prácticas pedagógicas constituyen espacios de exploración que retroalimentan los procesos de creación escénica.

En el final de su introducción, los autores reconocen como un tópico recurrente el cuestionamiento del director como autoridad individual y homogénea. En el presente, la referencia común que se manifiesta en gran cantidad de directores europeos refiere a la noción de grupo y compañía, en la cual el trabajo con los actores y los escenógrafos resulta un aspecto fundamental. La pregunta acerca de las características que definen el rol de la dirección se mantiene por lo tanto abierta: el director ya no puede ser visto desde la autoridad de un individuo particular, "sino más bien como un constructo en el cual se articulan debates más extensos en torno a la intersección entre teatro, nación, estado y las estructuras más amplias en las que los espacios geográficos, políticos y culturales se intersectan o colisionan. La dirección se muestra como una función y una profesión, una marca y un proceso, un encuentro y una fuerza de mercado" (Rebellato y Delgado, 2010: 21) ${ }^{7}$.

"The director may be a brand, but it is a brand cultivated by a team. This volume does not seek to see the director as a homogeneous individual but rather as a construct that itself articulates wider debates around the intersections between theatre, nation, state and the broader structures through which geographical, political and cultural spaces intersect or collide. Directing is shown to be both a function and a profession, a brand and a process, an encounter and a market force" (la traducción es nuestra).
Resulta significativo observar en las apreciaciones finales de Rebellato y Delgado la incidencia que los esquemas institucionales adquieren en la configuración de la dirección como profesión. Este aspecto será clave para considerar las definiciones que Serge Proust $(2012,2019)$-desde un marco teórico asentado en la sociología del arte- elabora en torno a la dirección teatral a partir del concepto de artificación (Heinich y Shapiro, 2012). La artificación define un proceso que delimita la frontera entre lo que se considera como artístico y lo que no, a partir de la interacción de diversos actores sociales. En el caso del teatro, se trata de reconocer cualidades estéticas sobre un fenómeno específico que no parte de un objeto preexistente, sino de una realidad inmaterial. La figura del director se distingue del resto de los agentes involucrados en la producción teatral: en él se delega la capacidad de unificar diversos componentes (la iluminación, la actuación, la escenografía, etc.), la intelectualización de la actividad a partir de la elaboración de escritos teóricos y -en el caso particular de la historia teatral francesa- la monopolización de un conjunto de recursos públicos. El proceso de artificación le otorga también al director el estatuto de autor, en una abierta disputa por la legitimidad que lo enfrenta contra dramaturgos y actores. Según el sociólogo, si bien hasta mediados del siglo XX el arte teatral estuvo íntimamente ligado al espacio literario, desde la década del 50 una serie de innovaciones técnicas y teóricas trajo aparejada la redefinición de los vínculos entre la dirección y el texto dramático, afirmando posturas iconoclastas basadas en la transformación de las secuencias textuales y en la modificación de su semántica.

A la hora de caracterizar el trabajo de la dirección escénica y sus mecanismos de legitimación, Proust observa que, si bien la performance teatral se asienta en aspectos materiales, el reconocimiento de sus habilidades refiere a su capacidad de interrelacionar y combinar estas formas para gestar una nueva realidad inmaterial. A su vez, la intervención estatal durante la década del 50 marcó en Francia un cambio de la relación entablada entre la dirección y los marcos institucionales. Con la creación del Ministerio de Asuntos Culturales en 1959 se define un sistema administrativo que evalúa la calidad de las producciones de los directores teatrales, estableciendo jerarquías y regulando sus trayectorias. De esta manera, el apoyo recibido por los fondos públicos le otorga a los directores la posibilidad de adquirir un grado de poder y preeminencia por encima de los dramaturgos y una enorme libertad creativa que prescinde de cualquier demanda de rentabilidad. En este contexto, el reconocimiento del director teatral en tanto artista y su prestigio social es consecuencia de las sucesivas revoluciones estéticas, de las transformaciones en los objetos de estudio definidos por la investigación académica y, sobre todo, el producto de una extensa intervención estatal. Sin embargo, a pesar del status conquistado en el presente, las dificultades en torno a la definición del oficio de la dirección persisten, producto de la inmaterialidad de su objeto y del progresivo incremento de nuevas profesiones teatrales que reclaman su reconocimiento, disputando los alcances prácticos delegados en la dirección. El oficio de la dirección desafía también la comprensión del trabajo artístico desarrollado en Occidente, que, según Hannah Arendt, reconoce en los productos estéticos su posibilidad de permanencia y preservación (Proust, 2019: 347). 
Proust concluye que "la dominación simbólica y física ejercida actualmente en el teatro público francés por los directores de teatro sobre todos los demás participantes en producciones teatrales es el resultado de una larga labor de artificación que se ha venido realizando durante más de un siglo" (347). Sin embargo, el autor confronta dos miradas sobre la proyección del oficio de la dirección en el futuro: aquellas que reconocen en el director un paso más en la evolución del arte teatral, y quienes observan en los procesos de artificación que le dieron nacimiento solo un fenómeno contingente y efímero. Desde esta perspectiva, no es posible entonces concebir la dirección teatral por fuera de los marcos institucionales que la consolidaron.

\section{TEORÍA DE LA REgIE: MEDIACIÓN Y PENSAMIENTO}

Frente a la comprensión del oficio de la dirección teatral bajo los paradigmas de la mise-en-scène, el autourismo y la artificación, en Directing Scenes and Senses: The Thinking of Regie (2015), el investigador alemán Peter Boenisch elabora el concepto de Regie, caracterizando la dirección teatral como un ejercicio de mediación y una forma de pensamiento. Para desarrollar este concepto, Boenisch se sirve de un amplio andamiaje conceptual en el que sintetiza los aportes teóricos de Jacques Rancière, el principio del pensamiento especulativo hegeliano, la teoría estética de Schiller y los estudios de la teatralidad desarrollados por Rudolf Münz y Helmar Schramm en la década del setenta. Centrándose en el desarrollo del oficio de la dirección en Alemania, Boenisch se distancia de las definiciones elaboradas por Pavis y define la Regie como una "práctica relacional de renegociación y de puesta en relación de textos y teatro, de escenas y sentidos, de performances y audiencias, de dirigir-producir y espectar teatro, que se apoya en la forma y la estructura del teatro como una técnica y una institución cultural dentro del 'régimen estético del arte"”. El concepto de Regie describe de manera más abarcativa el trabajo de la dirección teatral, en tanto ésta no se reduce a una organización del conjunto de signos que la obra produce en el escenario, ni tampoco se limita a un ejercicio de traducción y ejecución. La clave de este trabajo se encuentra en un ejercicio de mediación, al considerar que la producción teatral no es la interpretación del texto o las operaciones intangibles del director, sino el encuentro entre tradiciones y memorias culturales diversas. La Regie opera también al nivel de lo sensible, a diferencia del concepto de "dirigir", que indica la condición práctica en la construcción de un espectáculo, y de mise-en-scène, que alude a una dimensión analítica, en la cual se describe la transformación de un texto en una experiencia multisensorial. Boenisch afirma que el advenimiento de la Regie es la manifestación teatral del "régimen estético de las artes" (Rancière, 2005, 2013), un modo de identificación específico de las prácticas artísticas que se deshace la correlación entre los temas y los modos de representación. De esta manera, la obra "aparece a través de una experiencia específica que suspende las conexiones ordinarias no solamente entre apariencia y realidad, sino también entre forma y materia, actividad y pasividad, entendimiento y sensibilidad" (2005: 24). A diferencia de Pavis - que define la emergencia de la dirección teatral a partir de 1880-Boenisch identifica el surgimiento de este oficio hacia 1771, en el trabajo de Herr Stephanie der Ältere, Heinrich Laube, Franz von DingeIstedt o Johann Wolfgang von Goethe. El nuevo rol del regisseur marca una rápida evolución en la cual éste abandona sus tareas orientadas a la organización administrativa y financiera de los ensayos hacia una función propiamente artística, que le otorga una dirección a la interpretación y la performance de los actores. La operación específica ejecutada por la Regie remite a una práctica de mediación en la cual se pone en relación el texto escrito con el momento presente en el cual la audiencia lo observa y lo experimen-

“(..) It is a fundamentally relational practice of renegotiating and relating texts and theatre, scenes and senses, performances and audiences, directing/producing and spectacting theatre, which sits in the very form and structure of theatre as a cultural technique and as a cultural institution within the "aesthetic regime of art" (Against authority: the deadlock of 'director's theatre'. Las itálicas corresponden al original. La traducción es nuestra). 
ta. De esta manera, el enlace entre el ejercicio de presentación, ejecución y expectación toma la forma, siguiendo la terminología de Rancière, de un nuevo "reparto de lo sensible", una nueva configuración de los horizontes culturales que definen los modos, las convenciones y los límites de lo pensable, lo visible, lo decible y lo perceptible al interior de una comunidad determinada. Boenisch se detiene también en la dimensión y los alcances que el concepto de "lo sensible" adquiere para el filósofo francés: el espectro semántico de este concepto alude tanto a aquello que produce sentido como a lo que es percibido por nuestros sentidos. A la vez, esta nueva comprensión de la práctica directorial le otorga a la audiencia un rol central: la dirección y la expectación constituyen actividades estructurales y complementarias en un intercambio sin jerarquías. Al intervenir en la estructura que describe el "reparto de lo sensible" la práctica estética que encarna la Regie adquiere para Boenisch el estatuto de una operación política y de un ejercicio disensual.

De la misma manera que Pavis describe las transformaciones que los Performance Studies introdujeron en la práctica y la teoría de la puesta en escena, Boenisch confronta el campo de estudios norteamericanos de la performance con las líneas de investigación de la escuela alemana y su concepto de "lo teatral" ("theatrality" "): mientras que la teoría norteamericana pone el acento en la pura "ejecución de una acción”, los estudios alemanes identifican la expectación como un aspecto insoslayable del fenómeno teatral. Para teóricos como Rudolf Münz y Helmar Schramm pensar la teatralidad supone regresar a la connotación que encierra el prefijo griego de la palabra thea: se trata del doble ejercicio de mostrar y mirar. Boenisch recupera de Schramm su comprensión de "lo teatral", entendido como las combinaciones históricamente específicas de tres agentes de la "energía cultural": la aisthesis (percepción), la kinesis (movimiento), y la semiosis (el sentido). La Regie encarna entonces "la fuerza cultural que pone en marcha un proceso teatral complejo y dinámico en el que los signos semióticos, el texto y el lenguaje se unen a las fuerzas de la kinesis, de la información móvil y" transportadora”, y de la aisthesis, su dirección de espectadores experimentados" ${ }^{10}$.

En tanto "fuerza cultural", la Regie comparte algunos principios estructurales del pensamiento especulativo tal como lo entendió Hegel, a partir de la tríada entre historicidad, reflexibilidad y universalidad (concreta), junto a los principios de mediación y negatividad. La Regie introduce la historicidad de los textos dramáticos puestos en escena, articulando una nueva comprensión del presente por medio del pasado. Mientras que la filosofía hegelina

A partir de los estudios desarrollados por Rudolf Münz (1998) y Helmar Schramm (1990) Boenisch afirma que el concepto de "lo teatral" implicó en el ámbito europeo una toma de postura contra la matriz canonizada del "teatro burgués". A la vez, el uso de este término, distinto del concepto más habitual de "teatralidad" ("theatricality"), pretende eludir un error historiográfico común, basado en la proyección de ideas o conceptos contemporáneos (fundamentalmente los de la historia teatral europea a partir del siglo XVIII) sobre diversas prácticas teatrales del pasado. En tercer lugar, la utilización de este término busca defender el teatro frente a las posiciones teóricas que lo definen como una práctica cultural anticuada y conservadora.

10 “(.) can be grasped as the cultural force that sets in motion a complex and dynamic theatral process where semiotics signs, text and language bind themselves to the forces of kinesis, of moving and "trasporting" information, and aisthesis - its address of experiencing spectators" (Theatrality: the theories of Rufold Münz and Helmar Schramm. La traducción es nuestra). marca una apertura a la realidad histórica, el pensamiento de la Regie transforma al teatro en un arte que se sitúa en su momento histórico y cuyo presente constituye su absoluta condición de posibilidad. La materialización de ese pasado en la escena proyecta una potencialidad que no se manifiesta en el presente inmediato. En paralelo, el principio de reflexividad se expresa en la experiencia estética en tanto los objetos y las prácticas artísticas se revelan como extraños a los modos perceptivos del régimen cotidiano, pero a la vez le permite al espectador reconocerse en ellos. Según Boenisch, el proceso reflexivo posibilita el desarrollo de la propia conciencia espiritual, de la totalidad de la "vida colectiva" (Jameson, 2013). La reflexividad solicita la constitución de una "mediación", que articula el tercer principio del pensamiento especulativo: la "universalidad concreta”. El trabajo de la Regie implica una negociación entre lo abstracto y la universalidad concreta, y cuestiona la comprensión del director como un autor que abusa del trabajo del dramaturgo en pos de la afirmación de su voluntad individual. En el ejercicio de la Regie se reconoce su carácter inmanente, en tanto supone una mediación históricamente situada. Estos tres elementos ponen de manifiesto la dimensión de "negatividad" que caracterizan, de forma simultánea, al pensamiento hegeliano y a la práctica de la dirección teatral: La Regie “niega” el texto dramático, pero no en el sentido de omitir su intención autorial o buscando reemplazar el trabajo del dramaturgo por el de la dirección, sino que más bien implica la desestabilización del texto como ley inmutable y como "significante maestro" (Lacan). A la vez, este principio cuestiona la comprensión binaria del texto como idea y la performance escénica como su materialidad. Al considerar la dimensión reflexiva como un aspecto inherente a la práctica de la Regie, Boenisch introduce un modo de lectura sobre las prácticas de dirección que se aleja de las teorías del auteurismo enunciadas en el apartado anterior.

Por último, el investigador observa en el pensamiento de Friederich Schiller los antecedentes que definen la Regie como una práctica de mediación estética. La evocación del filósofo alemán resulta central para iluminar la politicidad inherente a la dirección teatral. Boenisch rescata del pensamiento de Schiller tres ideas centrales: los conceptos de libertad, autonomía y juego. De las tres, el juego constituye el efecto más profundo de la práctica teatral. El jugar es una práctica estructurante de lo humano que quiebra una determinada "partición de los sensible", objetando la comprensión del mundo en términos puramente binarios y exclusivos. La dimensión autónoma que Schiller le reconoce a la práctica artística afirma en la experiencia estética el ejercicio de un vigoroso disenso sobre las formas de visibilidad y de enunciación hegemónicas. En este sentido, "la autonomía de la obra y la experiencia estética expresa el potencial de una redivisión de lo sensible hegemónico en su sentido más pleno: un cambio del orden político y estético que es experimentado en su esencia de manera sensible" ${ }^{11}$. Para Schiller, la experiencia estética funda un territorio que afirma el verdadero sentido de libertad del hombre: el teatro encarna, en ese sentido, el sitio ideal de expresión de la libertad al equiparar forma y contenido, abstracción y fantasía, reflexión y representación. La Regie es también

The very autonomy of aesthetic play and experience expresses the potential for a redivisión of the hegemonic sensible in its fullest sense: a shift of the aesthetico-political order that is essentially sensibly experienced" (Beyond the 'moral institution': theatre as play. La traducción es nuestra). 
una fuerza transcrítica que señala una posición relacional y especulativa: integra en su ejercicio la dualidad que el prefijo thea encarna, y que remite de manera simultánea al concepto de teatro y de política. En este aspecto, Boenisch considera que las aproximaciones a la dirección teatral en términos de una mera práctica funcional o un oficio resultan insuficientes, aspecto que nos lleva a confrontar su teoría con las perspectivas genéticas en torno a la dirección teatral.

\section{LA DIRECCIÓN TEATRAL COMO PROCESO CREATIVO Y COG-} NITIVO

La pregunta por la definición de la práctica de la dirección teatral y sus funciones revela una mirada novedosa en el trabajo The director and directing: Craft, Process and Aesthetics in Contemporary Theatre, de Adam Ledger (2019). La perspectiva de Ledger resulta a la vez complementaria y diversa de la de Boenisch, ya que el investigador norteamericano se interna en el oficio de la producción y en el entramado de decisiones artísticas que operan en los procesos de creación de la dirección teatral. A partir de las premisas que definen la neuroestética, Ledger reconoce en la dirección teatral una forma de conocimiento "sobre el mundo y en el mundo". Adicionalmente, el autor utiliza una serie de categorías provenientes de la teoría de la creatividad, a fin de elaborar un mapa posible de los procesos creativos de la dirección. Junto a la figura del director como creador de la puesta en escena, maestro de actores y teórico, el investigador describe algunas funciones centrales que caracterizan al director contemporáneo: agente organizador de las tecnologías electrónicas que le dan forma a la escenografía contemporánea y, fundamentalmente, la consolidación de un tipo de artista que, en tanto creador, no se encuentra atado a la existencia de un texto previo. Ledger orienta también su estudio hacia la experiencia estética del espectador, a partir del concepto de "bucle autopoiético" (Fischer-Lichte, 2013), en el cual el significado del evento teatral emerge como un proceso compartido entre la audiencia y los hacedores del acontecimiento escénico (Ledger, 2019: 12). La articulación de los conceptos desarrollados por Ficher-Lichte y Boenisch le permiten a Ledger trascender la oposición entre la comprensión del director en tanto auteur o como un mero intérprete de las lógicas de sentido instauradas por el texto dramático. Desde una posición que reivindica el estudio empírico de la dirección teatral, Ledger elabora un inventario de las habilidades presentes en el oficio del director a partir de tres categorías: las que conciernen al actor, las referidas al espacio y las que se orientan hacia la configuración del espectáculo teatral en tanto evento. En primer lugar, todo director es el responsable de una definición metodológica para llevar adelante el trabajo con el actor; de forma simultánea, en él se delega una concepción espacial y el diseño del dispositivo escenográfico; el director es también el responsable de concebir la configuración de la experiencia potencial que, en tanto performance, el espectáculo manifiesta. En estas cualidades que definen sus tareas se pone de manifiesto la pericia de la dirección en interacción con el resto de los artistas teatrales. En tanto sujeto dedicado a la articulación de tareas y visiones artísticas heterogéneas, en el director convive un componente conativo (orientado a dirigir la voluntad de otros), emocional (su capacidad de percibir y articular la trama afectiva de los procesos creativos), y un "agente de cambio", capaz de elaborar operaciones de selección que negocian de manera constante con el contexto estético, político y las demandas de rentabilidad comercial. El director es también un sujeto artístico que cataliza nuevas formas de trabajo y nuevas definiciones estéticas.

En la construcción de una mirada que privilegia la dimensión genética de los espectáculos, Ledger pone el acento en lo poco que ha sido estudiada la dinámica del ensayo, laboratorio y espacio de ejecución primordial de 
la dirección. Para llevar adelante un estudio dispuesto a definir las tareas que caracterizan a la dirección teatral, Ledger considera fundamental la exploración de los modos de organización en las etapas de pre-producción y en las instancias de prueba con los actores en el espacio escénico. Estudiar estos fenómenos supone idear conceptos capaces de darle nombre y visibilidad a los procesos de creación por los que transita la dirección desde los orígenes mismos de su trabajo, y repensar el posicionamiento que el investigador teatral asume en la comprensión del fenómeno estudiado.

\section{CONCLUSIONES: HACIA UNA TEORÍA COMPARADA DE LA DI- RECCIÓN TEATRal En AmÉrica Latina}

El conjunto de perspectivas recogidas en torno al oficio de la dirección teatral nos permite formular una serie de conclusiones y esbozar un conjunto de interrogantes. En primer lugar, la dirección teatral es un fenómeno complejo que solicita para su comprensión una pluralidad de miradas en las que conviven enfoques filosóficos, semióticos, fenomenológicos, junto con aproximaciones sociológicas o modelos basados en la neuroestética y las teorías de la creatividad. Desde el marco conceptual y metodológico de la Poética comparada (Dubatti, 2010), consideramos que las miradas expuestas pueden asumir un carácter dialógico y complementario. Pensar una poética de la dirección teatral supone, desde nuestra perspectiva, la articulación de tres niveles: aquel que refiere a la dimensión del trabajo (el conjunto de directrices materiales, conceptuales, las técnicas y los procesos que describe la dirección teatral, así como también el análisis de los marcos institucionales en los que tiene lugar); junto a él, el aspecto estructural que el producto de la dirección teatral concibe y elabora, tanto en su dimensión inmanente como en su vínculo con instancias externas (la historia social y política); por último, la concepción teatral, elemento de análisis que opera en la modalización de las formas de trabajo y en las estructuras poéticas elaboradas por la dirección. Los tres niveles enunciados permiten reconocer en el estudio de la dirección las características que lo definen como un acto de creación y las particularidades que reviste el espectáculo en tanto producto y objeto de conocimiento. La tríada enunciada permite integrar aquellas aproximaciones centradas en el estudio de la dimensión genética de los espectáculos o de las dinámicas sociales que la dirección despliega (tal como se advierte en los trabajos de Ledger, Rebellato, Delgado y Proust), así como también la observación sobre el producto específico que la dirección concibe y elabora (la Mise-en-scène o la Regie en tanto objeto teórico).

Por otra parte, la perspectiva cognoscitiva de la dirección formulada por Ledger y Boenisch posibilita considerar el oficio de la dirección teatral a partir de los debates en torno a la relación entre el arte y el conocimiento (Deleuze y Guattari, 1997; Goodman, 1976, 2015). De forma complementaria, Delgado, Rebellato y Proust reconocen tres aspectos fundamentales para pensar el oficio de la dirección en el presente: aquel que refiere a su función pedagógica, al ejercicio intelectual y al diálogo entablado con los marcos institucionales del teatro. De manera complementaria, la comprensión de la dirección como dispositivo de disenso tal como lo enuncia Boenisch permite que nos interroguemos por las formas de intervención política que se advierten en el oficio de la dirección en los diversos contextos latinoamericanos en los que se ha desarrollado, atendiendo también a las variables de articulación entre las prácticas teatrales y los procesos históricos. Al concebir la dirección como un ejercicio de mediación que no queda subsumido al sistema de signos inscripto en la puesta en escena, es posible reconocer en ella una fuerza capaz de configurar nuevas sensibilidades, de producir "estructuras de sentimientos" (Williams, 1997), fundar comunidades afectivas e incidir en el medio social en el cual se desenvuelve. Sin definirlo de la misma manera, Ledger reconoce un potencial similar al concebir al director como un "agente de cambio", capaz de 
poner en cuestión las lógicas comerciales, políticas y estéticas que definen su trabajo.

Cada una de las teorías referidas en este estudio privilegian - de forma casi absoluta- aquellas experiencias que parten de la existencia de un texto dramático previo. En algunos marcos teóricos específicos, como el que enuncia Boenisch, esta condición resulta fundamental para considerar el alcance de sus definiciones. Vale la pena entonces interrogarse por las implicancias de una teoría de la dirección capaz de dar cuenta de aquellas experiencias teatrales que prescinden de manera total de un texto dramático pre-existente, fenómeno recurrente en la escena teatral latinoamericana de las últimas décadas. Algo similar podría decirse del carácter individual o colectivo que la dirección supone: si bien en un plano abstracto muchas de las definiciones abordadas conciben la dirección en términos colectivos, los ejemplos utilizados para refrendar su dimensión teórica insisten, en la mayoría de los casos, en la comprensión del director como un sujeto individual. A la vez, las construcciones teóricas indagadas elaboran sus marcos de análisis a partir de la observación de aquellas prácticas teatrales que poseen un alto grado de institucionalización, en contextos geográficos donde la presencia estatal en materia de incentivo y regulación cultural es alta. En el marco de una teoría situada, dispuesta a describir la pluralidad de las prácticas de la dirección teatral en los diversos contextos latinoamericanos, la comprensión de la dirección como una forma de pensamiento esbozada por Boenisch permite el desarrollo de un campo de estudios orientado al análisis sobre las formas de pensamiento teatral gestadas por los directores latinoamericanos y su interacción con las experiencias intelectuales presentes en su medio social y cultural. Se trata, por lo tanto, de reconocer las formas en las cuales la dirección afirma su identidad al interior de una pluralidad de territorios atravesados por procesos históricos y políticos singulares. Una historia de la dirección teatral en latinoamérica demanda entonces una perspectiva comparada, solicita un estudio anclado en sus manifestaciones territoriales (en contextos geográficos-históricos-culturales singulares), por relación y contraste con otros fenómenos territoriales o por la superación de la territorialidad como categoría (Dubatti, 2012). En el caso de la dirección latinoamericana, se vuelve necesario pensar el intercambio entre el desarrollo del oficio en el continente con los modelos configurados en Europa, al igual que sus apropiaciones y sus reelaboraciones, de acuerdo a las tradiciones y a las formas de organización que la dirección teatral asume en nuestro territorio. Esto implicará, a futuro, el desarrollo de un nuevo estudio que permita indagar sobre los paradigmas implícitos en los modelos de historización de la dirección teatral desarrollados en el continente latinoaméricano, varios de ellos nombrados en la introducción de este artículo.

Por último, resulta interesante observar de qué manera la dinámica relacional que define el oficio de la dirección teatral se pone de manifiesto en cada una de las teorías relevadas, a partir de la interacción que la figura del director entabla con el resto de los artistas y los agentes que conforman los procesos de producción teatral, o a través de la forma en que la propia materialidad del espectáculo impacta y se retroalimenta en el acto de expectación. Como hemos desarrollado anteriormente, Proust pone el acento en la dimensión propiamente inmaterial que define este oficio, a partir de las funciones de unificación e intelectualización asumidas por el trabajo de la dirección. Tal vez estas cualidades convierten a la dirección en un objeto escurridizo, oscilante entre una definición estrictamente material y la pura abstracción, entre la ausencia y la presencia, y reclaman para su comprensión una lógica fantasmática. Como advierte Derrida:

Lo que sucede entre dos, entre todos los «dos» que se quiera, como entre vida y muerte, siempre precisa, para mantenerse, de la intervención de algún fantasma. Entonces, habría que saber de espíritus. Incluso, si eso, lo espectral, no es. Incluso sobre todo si eso, que no es ni sustancia, ni esencia ni existencia, no está nunca presente como tal (2012: 10).

Ya sea a través de la comprensión del oficio de la dirección en su articulación con diversos marcos institucionales, de su consideración como dispositivo de pensamiento y conocimiento o de su capacidad de intervención política, los paradigmas enumerados describen algunos ejes centrales para la configuración de una historia de la dirección teatral en nuestro continente. Una historia que se encuentra en plena expansión. Una historia, quizá, habitada por fantasmas. 
ARgüEllo PItT, C. (2018). Dramaturgia de la dirección de escena. México: Paso de Gato.

BoEnISCH, P. (2015). Directing scenes and senses: The thinking of Regie. Manchester: Manchester University Press. E-book.

BRAdby, D., Williams, D. (1988). Director's Theatre. Nueva York: Macmillan Education.

Deleuze, G., Guattari, F. (1997). ¿Qué es la filosofía?. Barcelona: Anagrama.

DerRIDA, J. (2012). Espectros de Marx. Madrid: Trotta.

Dubattı, J. (2010). Filosofía del Teatro Il. Buenos Aires: Atuel.

Dubattı, J. (2012). Introducción a los estudios teatrales.Propedéutica. Buenos Aires: Atuel.

FISCHER-LICHTE, E. (2013). Estética de lo performativo. Madrid: Abada Editores.

Fukelman, M. (2018). Mujeres en la historia del movimiento de teatros independientes de Buenos Aires. Revista interdisciplinaria de Estudios de Género de El Colegio de México (4). Recuperado de: https://estudiosdegenero.colmex.mx/index.php/eg/article/view/290/175

Geirola, G. (2014). Arte y oficio del director teatral en América Latina: Argentina, Chile, Paraguay y Uruguay. Los Ángeles, Buenos Aires: Argus-a.

GeIRolA, G. (2015A). Arte y oficio del director teatral en América Latina: Colombia y Venezuela. Los Ángeles, Buenos Aires: Argus-a.

Geirola, G. (2015B). Arte y oficio del director teatral en América Latina: Puerto Rico y Republica Dominicana. Los Ángeles, Buenos Aires: Argus-a.

GeIrola, G. (2015C). Arte y oficio del director teatral en América Latina: Bolivia y Ecuador. Los Ángeles, Buenos Aires: Argus-a.

Goodman, N. (1976). Los lenguajes del arte. Barcelona: Paidós.

Goodman, N. (2015). Maneras de hacer mundos. Buenos Aires: Antonio Machado libros.

HeRAS, G. (2014). Los retos de la dirección de escena actual. México: Luciérnaga Azul.

Jameson, F. (2013). Valencias de la dialéctica. Buenos Aires: Eterna Cadencia.

Ledger, A. (2019). The director and directing: Craft, Process and Aesthetics in Contemporary Theatre. London: Palgrave Micmillian.

LozAno, E. (2008). Vigencia de la puesta en escena en el teatro contemporáneo del mundo. Telondefondo. Revista De Teoría Y Crítica Teatral, (7), 1-11. Recuperado de: http://revistascientificas.filo.uba.ar/index.php/telondefondo/article/view/9450

MARIN, F. (2018). Dirección teatral: del mundo del pensamiento al universo de las relaciones de grupo. Reflexiones en torno los procesos de escenificación del teatro independiente de Córdoba. Telondefondo. Revista De Teoría Y Crítica Teatral, 14(28), 94-106. Recuperado de: http://revistascientificas.filo.uba.ar/index.php/telondefondo/article/view/5480

MARIN, F. (2020). Concepciones y especificidad del rol de la dirección teatral. Un caso en el teatro independiente argentino, Investigación Teatral: revista de artes escénicas y performatividad 11(17).

Mauro, K. (2011). La técnica de actuación en Buenos Aires. Elementos para un modelo de análisis de la actuación teatral a partir del caso porteño. Inédita. 
Münz, R. (1998). Theatralität und Theater: Zur Hitoriographie von Theatralitätsgefügen. Berlin: Schwarzkopf \& Schwarzkopf.

Pavis, P. (2007). La mise en scène contemporaine. Origines, tendances, perspectives. París, Armand Colin.

Pavis, P. (2016). Diccionario de la performance y del teatro contemporáneo. México: Paso de Gato.

Pellettieri, O. (Dir.). (2001). Historia del Teatro Argentino en Buenos Aires. Volumen 1. Buenos Aires: Galerna.

Pellettieri, 0. (2001). Historia del Teatro Argentino en Buenos Aires. Volumen 5. Buenos Aires: Galerna.

Pellettieri, 0. (2002). Historia del Teatro Argentino en Buenos Aires. Volumen 2. Buenos Aires: Galerna.

Pellettieri, 0. (2003A). Historia del Teatro Argentino en Buenos Aires. Volumen 3. Buenos Aires: Galerna.

Pellettieri, O. (2003B). Historia del Teatro Argentino en Buenos Aires. Volumen 4. Buenos Aires: Galerna.

PinTA, M. (2013). Teatro expandido en el Di Tella. Buenos Aires: Biblos.

PRoust, S. (2012). Les metteurs en scène de théâtre entre réussite sociale et remise en cause ontologique, en N. Heinich et R. Shapiro, De l'artification. Enquêtes sur le passage à l'art, Paris, Éditions de l'École des Hautes Études en Sciences Sociales, 2012, 95-112.

Proust, S. (2019) “Portrait of the Theatre Director as an Artist”, Cultural Sociology, Vol. 13(3), 338-353.

SChramm, H. (1990). "Theatralität und Öffentlichkeit. Vorstudien zur Begrifsgeschichte von “Theater”, en Karlheinz et al. (Ed.), Ästhetische Grundbegriffe: Studien zu einem historischen Wörterbuch. Berlin Akademie Verlag, 202-242.

Szuchmacher, R. (2015). Lo incapturable. Buenos Aires: Penguin Random House.

Sidiropoulou, A. (2011). Authoring Performance: The Director in Contemporary Theatre. Nueva York: Palgrave McMillian.

Williams, R. (1997). Marxismo y literatura. Barcelona: Península 